\title{
KINERJA ORTHOGONAL FREQUENCY DIVISION MULTIPLE ACCESS (OFDMA) PADA TEKNOLOGI RADIO OVER FIBER (ROF)
}

\author{
Amalia Eka Rakhmania ${ }^{[1]}$, Sholeh Hadi Pramono ${ }^{[2]}$, Dwi Fadila Kurniawan ${ }^{[2]}$ \\ ${ }^{[1] J u r u s a n ~ T e k n i k ~ E l e k t r o, ~ P o l i t e k n i k ~ N e g e r i ~ M a l a n g ~}$ \\ ${ }^{[2] J u r u s a n ~ T e k n i k ~ E l e k t r o, ~ U n i v e r s i t a s ~ B r a w i j a y a ~ M a l a n g ~}$
}

\begin{abstract}
Amalia Eka Rakhmania, Sholeh Hadi Pramono, Dwi Fadila Kurniawan, in this paper explain that radio over Fiber $(R o F)$ is a technology that integrates wireless and wireline transmission system to transmit radio signal through optical fibre cable. This paper evaluates the performance of Orthogonal Frequency Division Multiple Access (OFDMA) implemented in RoF system for mobile WiMAX network. RoF channel model includes both optical fiber with Relative Intensity Noise, shot noise, thermal noise, and chromatic dispersion, and also wireless channel with Additive White Gaussian Noise (AWGN). Through simulation, signal to noise ratio (SNR), channel capacity, bit rate, and bit error rate (BER) with the influence of optical fiber length and wavelength. Result shows that optical fiber length is proportional to SNR, channel capacity, and bit rate but inversely proportional to BER. $1550 \mathrm{~nm}$ wavelength has better channel capacity but lesser bit rate than $1310 \mathrm{~nm}$.
\end{abstract}

Keywords: noise; performance; OFDMA; radio over fiber; wavelength

\section{PENDAHULUAN}

Perkembangan teknologi telekomunikasi salah satunya ditunjukkan dengan perkembangan teknik transmisi data. Saat ini teknologi wireless merupakan teknologi yang sering digunakan, tetapi teknologi ini masih memiliki beberapa kekurangan, salah satunya adalah semakin tingginya loss ketika jarak transmisinya semakin jauh, adanya attenuasi akibat atmosfir [1], serta jarak jangkau yang dibatasi oleh cell coverage masing-masing base station [2]. Teknologi wireline, misalnya serat optik, dapat menjangkau daerah yang jauh maupun area di dalam gedung, tetapi apabila penarikan kabel dari sentral terlalu jauh, dikhawatirkan mengalami rugi-rugi yang cukup tinggi. Untuk mengatasi permasalahan tersebut, dikembangkan suatu teknologi penggabungan antara wireless dan wireline, yaitu teknologi Radio over Fiber (RoF).

Konsep RoF bertujuan untuk mengirimkan informasi melalui kabel serat optik dengan melakukan modulasi pada cahaya menggunakan sinyal radio[3]. Proses modulasi intensitas cahaya sumber laser tanpa mengubah format modulasi, walaupun proses ini hanya mungkin dilakukan pada fiber optik silika yang menawarkan bandwidth yang lebar [4]. Proses ini dilakukan pada central gateway, sehingga perangkat di dekat user lebih sederhana. Akibatnya, sistem RoF membutuhkan lebih sedikit biaya dibanding dengan sistem radio frekuensi tradisional [5].

RoF mendapat banyak perhatian karena banyaknya permintaan kapasitas maupun luasnya daerah cakupan serta pengembangan base station yang lebih sederhana. Meskipun demikian, ada beberapa kelemahan yang terdapat pada sistem RoF yaitu adanya distorsi nonlinier yang sebagian besar disebabkan oleh sifat nonlinier dari laser diode dan dispersi kromatik dari serat optik dan noise yang dibangkitkan oleh perangkat pengirim [6].

Integrasi OFDMA dengan RoF diharapkan dapat memberikan solusi untuk teknologi sebelumnya. Penelitian mengenai RoF lebih terfokus pada kinerja OFDM pada sistem RoF [1], [6]-[11]. Sedangkan [12] melakukan evaluasi sensitivitas penerima RoF terhadap sinyal OFDMA serta kinerja sinyal radio frekuensi. Integrasi OFDMA dengan Wavelength Division Multiplexing (WDM) dilihat dari resource allocation dievaluasi pada [13]. Untuk melakukan implementasi OFDMA pada RoF, sebelumnya harus diketahui seberapa baik kinerja OFDMA pada ROF. Penelitian ini bertujuan untuk menganalisis kinerja OFDMA pada RoF, dengan parameter performansi yang diamati yaitu signal to noise ratio (SNR), kapasitas kanal, bit rate, serta bit error rate sistem OFDMA pada radio over fiber.

\section{METODE PENELITIAN}

Metode perhitungan dan analisis data yang digunakan pada penelitian ini adalah melalui pengambilan nilai parameter data sekunder dan melakukan pendekatan matematis melalui simulasi menggunakan software. Sistem yang akan dianalisa dilihat dari sisi downlink dan dimodelkan sesuai dengan Gambar 1.

Gambar 1 menggambarkan model sistem yang digunakan untuk analisis dalam penelitian ini. Performansi sistem dihitung di sisi user (downlink). Proses transmisi dari central base station menuju radio access point dihubungkan melalui serat optik. Rugi-rugi yang terjadi dalam serat optik diperlihatkan pada gambar. Rugi-rugi propagasi dan kanal noise AWGN terjadi ketika transmisi dilakukan dari radio access point ke mobile station. Gambar 1 juga memperlihatkan beberapa variabel yang digunakan dalam perhitungan sistem. 


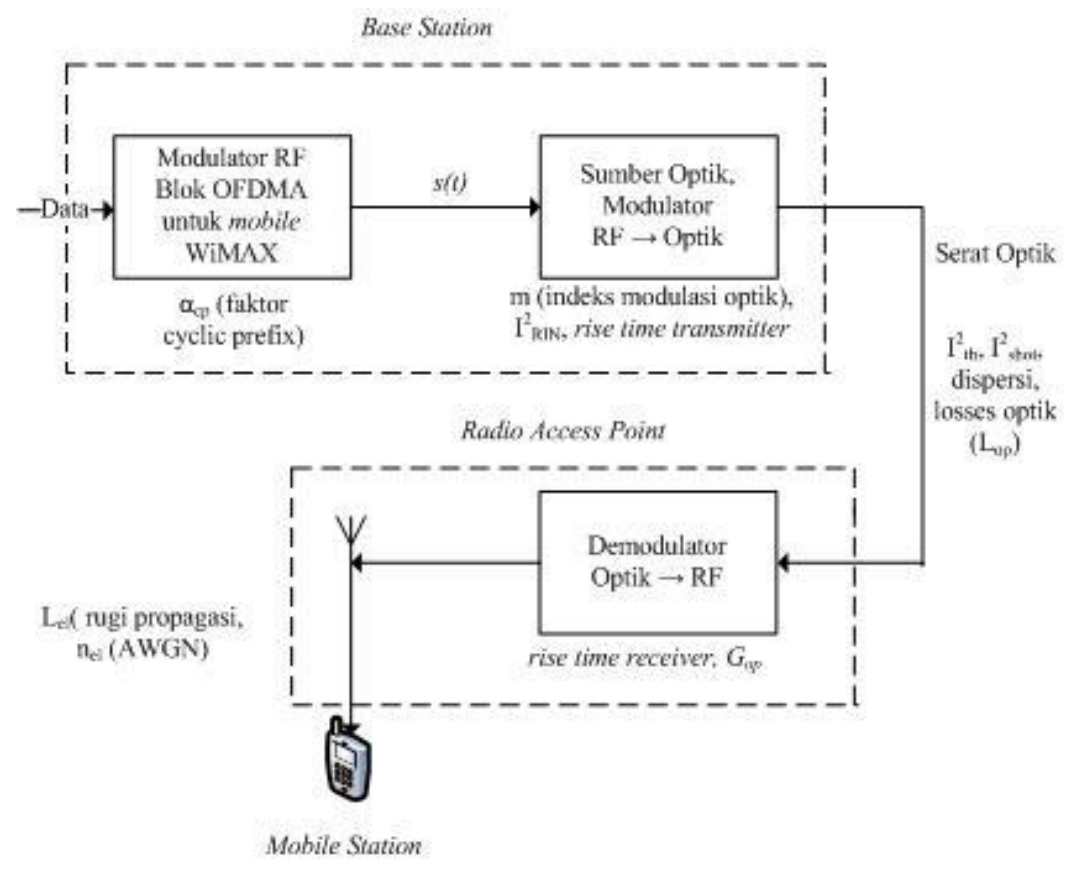

Gambar 1. Pemodelan Sistem

Algoritma perhitungan kinerja sistem dilakukan sesuai dengan parameter yang dihitung, yaitu SNR sistem, kapasitas kanal, bit rate, dan bit error rate.

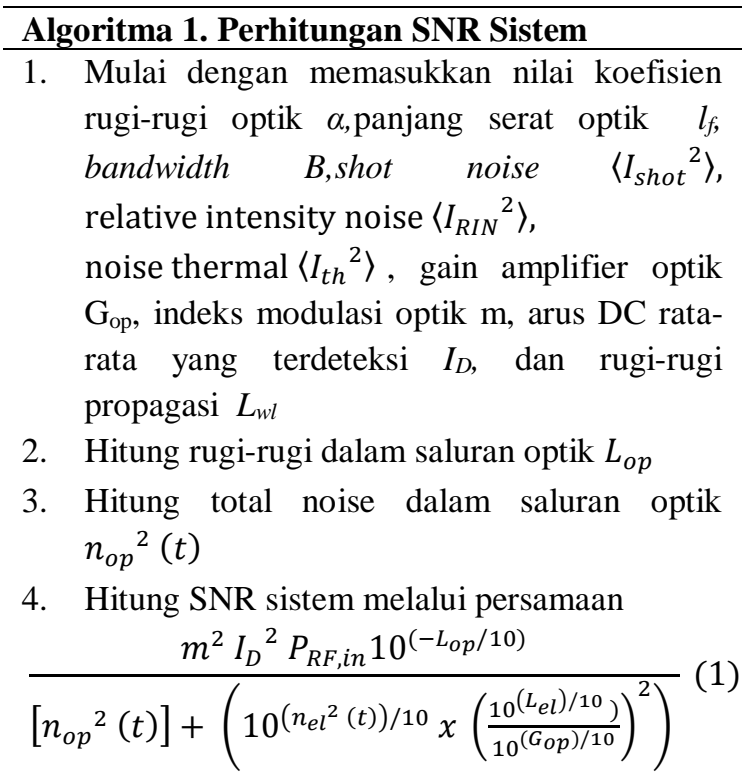

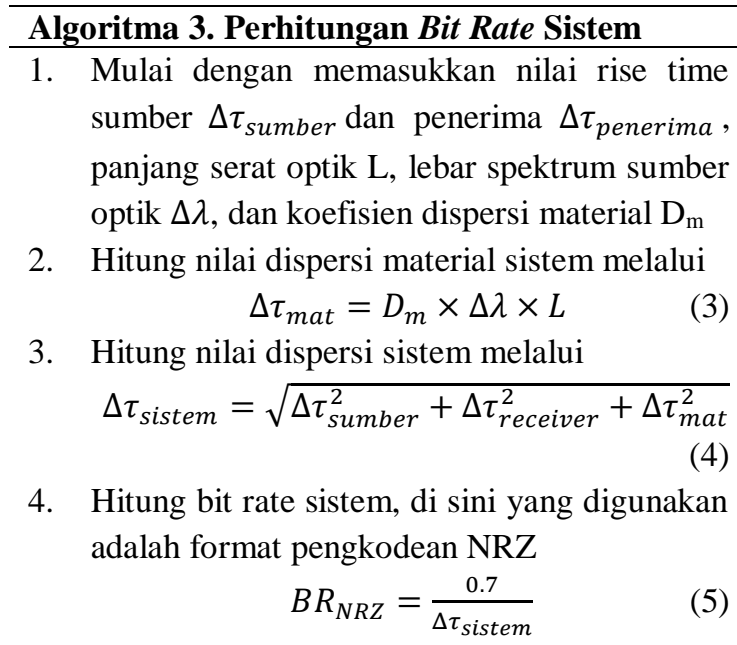

\section{Algoritma 4. Perhitungan BER Sistem \\ 1. Mulai dengan memasukkan nilai SNR sistem dari algoritma pertama \\ 2. Hitung nilai BER sistem melalui$$
\mathrm{BER}=\frac{1}{2} \operatorname{erfc}\left(\sqrt{S N R_{\text {sistem }}}\right)
$$

Kelebihan dari sistem transmisi multicarrier OFDMA adalah dapat mengefisienkan penggunaan bandwidth[14]. Selain itu sistem OFDMA dapat menjaga setiap subcarrier yang satu dengan yang lain agar tetap orthogonal dan mencegah terjadinya interferensi (ISI dan ICI) pada sistem, dengan menggunakan cyclic prefix $(\mathrm{CP})$. Cyclic prefix $(\mathrm{CP})$ merupakan duplikat bagian akhir dari simbol OFDMA untuk menghilangkan delay spread yang 
terjadi antar data yang saling tumpang tindih. Berdasarkan aturan yang telah ditetapkan bahwa delay spread tidak boleh melebihi $10 \%$ dari panjang simbol OFDMA agar nilai BER tetap kecil yaitu bernilai $10^{-3}$ bahkan kurang. Dengan demikian interval CP harus lebih besar atau sama dengan delay spread maksimum $\left(T_{c p} \geq 2 \tau\right)$ agar orthogonalitas antar subcarrier tetap terjaga. Pada model OFDMA untuk standar IEEE 802.16, dinyatakan bahwa panjang symbol $102.9 \mu \mathrm{s}$ dengan durasi symbol $91.4 \mu \mathrm{s}$, sehingga panjang CP yang digunakan untuk analisis adalah:

$$
\begin{aligned}
\alpha_{c p}=T_{c p} / T_{b}= & \left(T_{s}-T_{b}\right) / T_{b} \\
= & (102.9-91.4) / 91.4=1 / 8 \\
= & 12.5 \%
\end{aligned}
$$

CP yang digunakan adalah1/8 (12.5\%) dari durasi simbol OFDMA untuk menoleransi delay spread mencapai $11.4 \mu \mathrm{s}$, berdasarkan model OFDMA pada standar IEEE 802.16 [15].

Signal to noise ratio dihitung di sisi receiver (user) dengan pemodelan sistem berdasarkan propagasinya. SNR merupakan perbandingan antara daya sinyal yang diterima di sisi user dengan noise total yang dialami oleh sinyal. Sinyal $r(t)$ terdiri dari dua komponen, yaitu sinyal $s(t)$ dan noise total $n(t)$.

[16] menyatakan bahwa:

$$
r(t)=D \cdot s(t)+n(t)
$$

$$
\begin{aligned}
& D=m I_{D} 10^{-L_{o p} / 10} \frac{G_{o p}}{L_{w l}} \\
& n(t)=\frac{n_{o p}(t) G_{o p}}{L_{w l}}+n_{w l}(t)
\end{aligned}
$$

dengan:

$m=$ indeks modulasi optik

$I_{D}=$ arus yang terdeteksi oleh detector

$G_{o p}=$ gain optik pada radio access point

$L_{e l}=$ rugi-rugi pathloss

$n_{o p}=$ noise saluran optik, yang terdiri dari thermal noise, shot noise, serta RIN

$n e_{l}=$ noise wireless $(\mathrm{AWGN})$

Sehingga daya sinyal $r(t)$ juga terdiri dari daya sinyal dan daya noise, yaitu

$$
E\left[r^{2}(t)\right]=E\left[r_{s}^{2}(t)\right]+E\left[r_{n}^{2}(t)\right](10)
$$

Dari substitusi antara persamaan (7) dengan persamaan (8) didapatkan:

$$
\begin{aligned}
& E\left[{r_{s}}^{2}(t)\right]=m^{2} I_{D}{ }^{2} 10^{-L_{o p} / 10}\left(\frac{G_{o p}}{L_{e l}}\right)^{2} E\left[s^{2}(t)\right] \\
& E\left[r_{n}{ }^{2}(t)\right]=\left(\frac{G_{o p}}{L_{e l}}\right)^{2} E\left[n_{o p}{ }^{2}(t)\right]+E\left[n_{e l}{ }^{2}(t)\right]
\end{aligned}
$$

\begin{tabular}{|c|c|}
\hline Parameter & Value \\
\hline Frekuensi Operasi & $2300 \mathrm{MHz}$ \\
\hline Duplex & TDD \\
\hline Bandwidth kanal & $5 \mathrm{MHz}$ \\
\hline Teknik modulasi & $\begin{array}{l}\text { QPSK, 16-QAM, 64- } \\
\text { QAM }\end{array}$ \\
\hline Radius Cell & $2-5$ kilometers \\
\hline Tinggi Base station & 32 meters \\
\hline Tinggi Mobile Terminal & 1,5 meters \\
\hline $\begin{array}{l}\text { BS Maximum Power } \\
\text { Amplifier Power }\end{array}$ & $35 \mathrm{dBm}$ \\
\hline BS Antenna Gain & $16 \mathrm{dBi}$ \\
\hline MS Antenna Gain & $0 \mathrm{dBi}$ \\
\hline $\begin{array}{l}\text { Mobile Terminal } \\
\text { Maximum PA power }\end{array}$ & $23 \mathrm{dBm}$ \\
\hline Operating Temperature & $0^{\circ} \mathrm{C}-40^{\circ} \mathrm{C}$ \\
\hline
\end{tabular}

Jika SNR didefinisikan sebagai perbandingan antara daya sinyal yang diterima dengan daya noise yang dialami sesuai persamaan (13)

$$
S N R=\frac{E\left[r_{s}^{2}(t)\right]}{E\left[r_{n}^{2}(t)\right]}
$$

Sehingga didapatkan nilai SNR sesuai dengan persamaan (1).
Tabel 1 Spesifikasi Mobile WiMax 802.16e [17]

Selain spesifikasi mobile WiMAX, digunakan juga spesifikasi teknologi radio over fiber pada Tabel 2 .

Tabel 2 Spesifikasi Teknologi Radio over Fiber[18]

\begin{tabular}{ll}
\hline Parameter & Nilai \\
\hline Suhu Referensi $(\mathrm{T})$ & $300 \mathrm{~K}$ \\
Rise time transmitter & $16 \mathrm{psec}$ \\
$\left(\Delta \tau_{\text {source }} \quad \begin{array}{l}\text { Receiver }\left(\Delta \tau_{\text {receiver }}\right) \\
\text { Rise time rec }\end{array}\right.$ & $24 \mathrm{psec}$ \\
RIN (Relative Intensity & $-155 \mathrm{~dB} / \mathrm{Hz}$ \\
Noise) & $1 \mathrm{~mm} \leq \lambda \leq 1.5 \mathrm{~mm}$ \\
Panjang gelombang $(\lambda)$ & $0.2 \mathrm{~W} \leq \mathrm{P}_{0} \leq 0.597 \mathrm{~W}$ \\
Daya optik rata-rata $\left(\mathrm{P}_{0}\right)$ & $0.1 \leq \mathrm{m} \leq 0.9$ \\
Indeks modulasi optik $(\mathrm{m})$ & $0.12 \mathrm{~mW} / \mathrm{mA}$ \\
Gain modulasi laser $\left(\mathrm{G}_{\mathrm{m}}\right)$ & $0.75 \mathrm{~mA} / \mathrm{mW}$ \\
Responsivitas detektor $(\rho)$ &
\end{tabular}

\section{HASIL DAN PEMBAHASAN}

Kinerja OFDMA pada teknologi radio over fiber yang dibahas dalam penelitian ini memiliki variabel bebas panjang serat optik, bandwidth sistem, serta panjang gelombang yang digunakan. Performansi yang diamati meliputi signal-to-noise ratio (SNR), kapasitas kanal, bit rate, dan bit error rate (BER) teknologi RoF yang menggunakan teknik multiple access OFDMA.

Parameter yang digunakan untuk menganalisis kinerja teknologi radio over fiber yang menggunakan sistem mobile WiMAX dengan penerapan OFDMA adalah menggunakan standar IEEE 802.16e. Hasil simulasi, analisis dan pembahasan diuraikan sebagai berikut: 


\section{Analisa SNR Sistem}

Kanal noise yang digunakan dalam menghitung SNR terdiri dari kanal optik dan kanal wireless. Kanal wireless terdiri dari noise AWGN serta rugi-rugi propagasi ruang bebas.

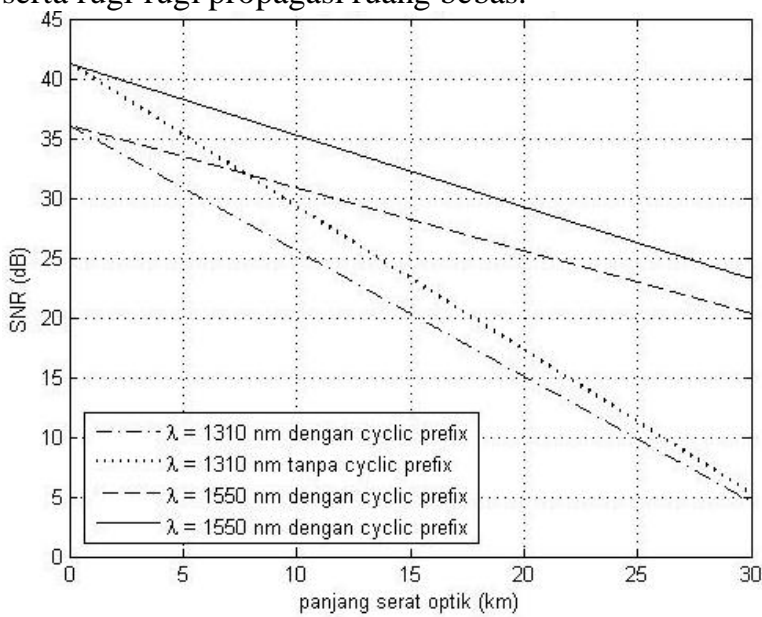

Gambar 2. Pengaruh panjang serat optik terhadap SNR Sistem

Gambar 2 memperlihatkan bahwa untuk transmisi dengan panjang gelombang yang sama, nilai $\mathrm{SNR}_{\text {sistem }}$ OFDMA dengan cyclic prefix lebih kecil jika dibandingkan dengan $\mathrm{SNR}_{\text {sistem }}$ OFDMA tanpa cyclic prefix. Pemisahan cyclic prefix pada penerima menyebabkan rugi-rugi energi yang berdampak pada penurunan SNR.

Semakin panjang serat optik yang digunakan, nilai SNR $_{\text {sistem akan semakin kecil, karena losses yang }}$ terjadi dalam proses transmisi semakin besar. Panjang serat optik berbanding lurus dengan nilai losses optik.

Pada panjang serat optik yang sama, nilai SNR $_{\text {sistem }}$ untuk panjang gelombang $1310 \mathrm{~nm}$ lebih kecil jika dibandingkan dengan panjang gelombang $1550 \mathrm{~nm}$. Karena nilai $L_{o p}$ yang dihasilkan panjang gelombang $1310 \mathrm{~nm}$ lebih kecil jika dibandingkan dengan $L_{o p}$ untuk panjang gelombang $1550 \mathrm{~nm}$. Hal ini sesuai dengan persamaan matematis rugi-rugi optik $L_{o p}$ di mana nilai koefisien redaman untuk panjang gelombang 1550 lebih kecil jika dibandingkan dengan koefisien redaman untuk panjang gelombang $1310 \mathrm{~nm}$.

\section{Analisa Kapasitas Kanal Sistem}

Perhitungan analisis kapasitas kanal sistem menggunakan teorema Shannon. Untuk memperoleh kapasitas kanal sistem maka dibutuhkan parameter $\mathrm{SNR}_{\text {sistem }}$ serta bandwidth sinyal pada saluran optik. Nilai bandwidth sinyal dalam saluran optik, untuk panjang serat optik $10 \mathrm{~km}$ dan panjang gelombang $1310 \mathrm{~nm}$ ditentukan dengan:

$$
\begin{gathered}
\Delta \tau_{\text {mat }}=D_{m} \times \Delta \lambda \times L \\
\Delta \tau_{\text {mat }}=14 \times 0.1 \times 10=14 \\
\Delta \tau_{\text {sistem }}=\sqrt{\left(\Delta \tau_{\text {sumber }}\right)^{2}+\left(\Delta \tau_{\text {receiver }}\right)^{2}+\left(\Delta \tau_{\text {mat }}\right)^{2}} \\
\Delta \tau_{\text {sistem }}=\sqrt{(16)^{2}+(25)^{2}+(14)^{2}} \\
=32.82 \mathrm{psec}
\end{gathered}
$$

$$
\begin{aligned}
& B W_{\text {sig }}=\frac{0.44}{\Delta \tau_{\text {sistem } x L}} \\
& B W_{\text {sig }}=\frac{0.44}{32.82 \times 10}=1.34 \mathrm{GHz}
\end{aligned}
$$

Gambar 3 menunjukkan bahwa nilai kapasitas kanal berubah secara logaritmik terhadap perubahan panjang serat optik yang digunakan karena SNR $_{\text {sistem }}$ berubah secara logaritmik terhadap panjang serat optik. Semakin besar panjang serat optik yang digunakan, kapasitas kanal sistem semakin kecil, karena nilai $\mathrm{SNR}_{\text {sistem }}$ serta bandwidth untuk serat optik yang lebih panjang juga semakin kecil. Sedangkan untuk panjang serat optik yang sama, panjang gelombang $1310 \mathrm{~nm}$ memiliki kapasitas kanal yang lebih besar dibandingkan dengan panjang gelombang $1550 \mathrm{~nm}$, perbedaan nilai ini disebabkan perbedaan nilai $\mathrm{SNR}_{\text {sistem }}$ dan bandwidth. Untuk panjang gelombang $1310 \mathrm{~nm}, \mathrm{SNR}_{\text {sistem }}$ lebih kecil, akibat dari koefisien redaman optik yang lebih besar, tetapi bandwidth sistem lebih besar karena koefisien dispersi panjang gelombang $1310 \mathrm{~nm}$ lebih kecil.

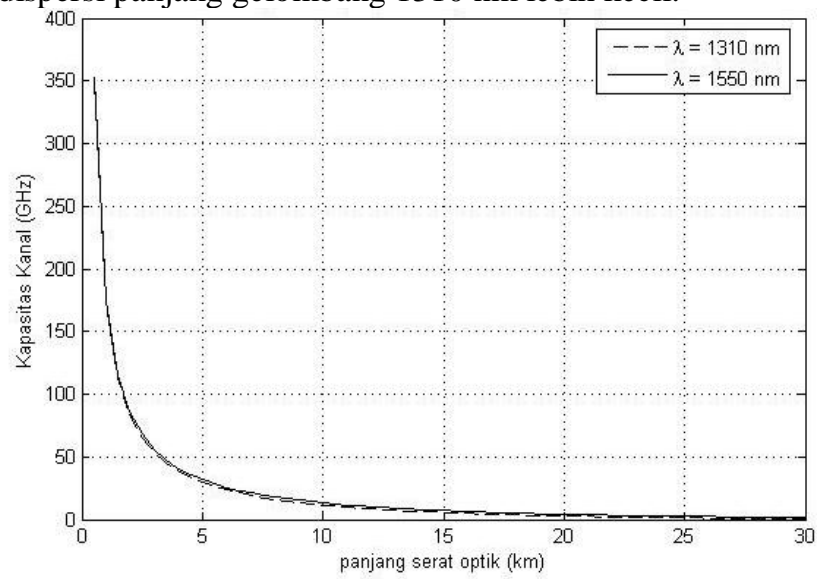

Gambar 3. Pengaruh panjang serat optik terhadap kapasitas kanal

Analisa Bit Rate Sistem

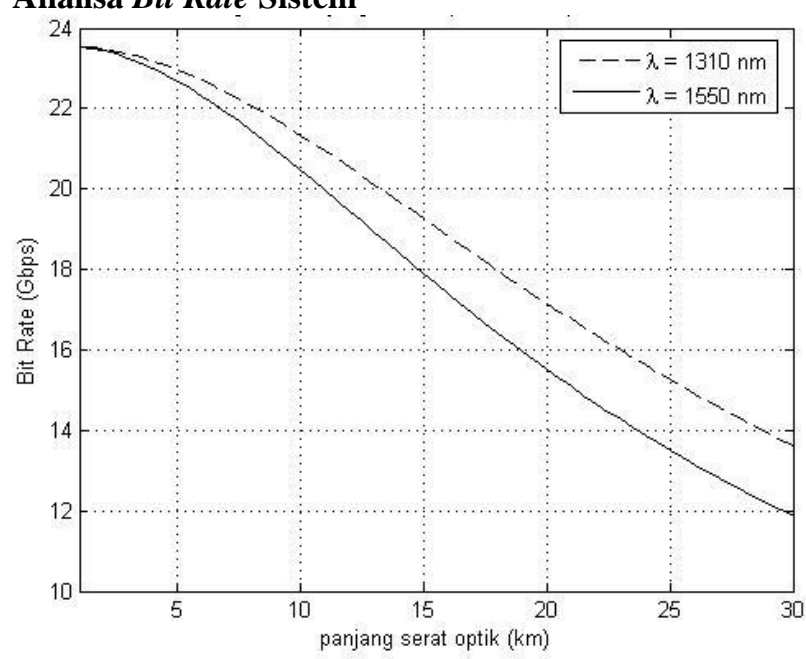

Gambar 4. Pengaruh panjang serat optik terhadap bit rate sistem

Gambar 4 menunjukkan hubungan antara panjang serat optik yang digunakan dengan bit rate dalam kanal optik. Panjang serat optik berbanding terbalik 
dengan bit rate sistem dalam kanal optik, semakin besar panjang serat optik yang digunakan, semakin kecil bit rate sistem dalam saluran optik. Kondisi ini dikarenakan semakin besar panjang serat optik yang digunakan, nilai dispersi material sistem semakin besar, sehingga bit rate semakin kecil. Sedangkan untuk nilai panjang serat optik yang sama, panjang gelombang $1310 \mathrm{~nm}$ memiliki bit rate yang lebih tinggi daripada panjang gelombang $1550 \mathrm{~nm}$, hal ini disebabkan panjang gelombang $1310 \mathrm{~nm}$ memiliki nilai koefisien dispersi yang lebih kecil dibandingkan dengan koefisien dispersi pada panjang gelombang $1550 \mathrm{~nm}$.

\section{Analisa BER Sistem}

Bit Error Rate (BER) merupakan perbandingan nilai bit yang salah saat proses transmisi, dihitung di sisi receiver. Hubungan panjang serat optik terhadap BER sistem ditampilkan pada Gambar 5.

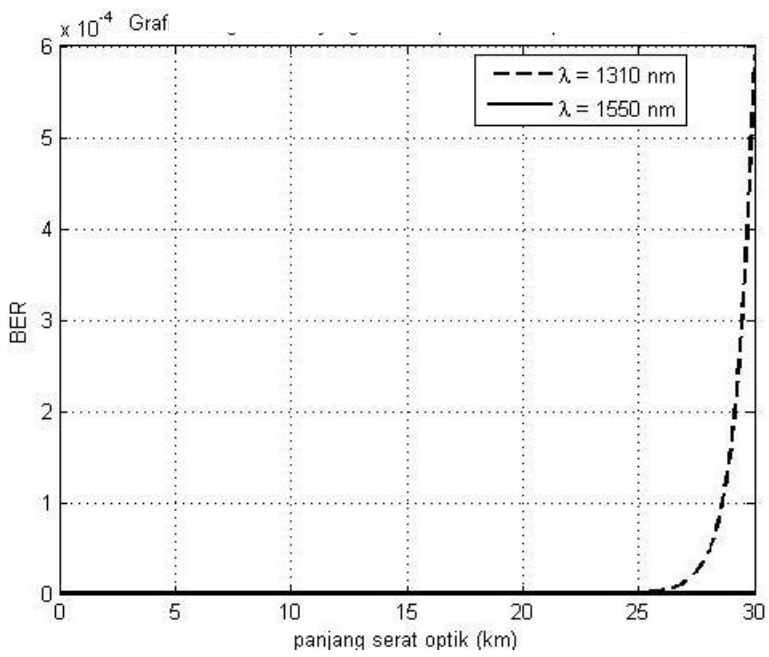

Gambar 5. Pengaruh panjang serat optik terhadap BER

Pada Gambar 9 dapat dilihat bahwa semakin besar panjang serat optik yang digunakan, semakin besar BER yang dihasilkan, dengan kata lain nilai BER berbanding lurus dengan panjang serat optik.

Untuk panjang serat optik yang sama, nilai BER panjang gelombang $1550 \mathrm{~nm}$ jauh lebih kecil jika dibandingkan dengan BER untuk panjang gelombang $1310 \mathrm{~nm}$. Hal ini karena nilai SNR sistem panjang gelombang $1550 \mathrm{~nm}$ lebih tinggi.

Nilai BER yang diharapkan adalah nilai BER yang kecil, karena nilai BER yang kecil berarti hanya sedikit kesalahan yang terjadi dalam transmisi, dengan kata lain data yang diterima semakin menyerupai data yang dikirimkan.

\section{KESIMPULAN}

Berdasarkan hasil analisis dan simulasi perhitungan, dapat disimpulkan bahwa seiring dengan meningkatnya panjang serat optik yang digunakan,

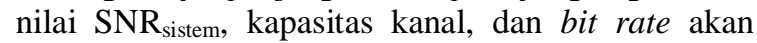
menurun seiring dengan panjang serat optik yang digunakan. Sebaliknya, nilai BER akan meningkat seiring dengan semakin besarnya panjang serat optik. $\mathrm{SNR}_{\text {sistem }}$ dan kapasitas kanal untuk panjang gelombang $1550 \mathrm{~nm}$ lebih tinggi dibandingkan SNR untuk panjang gelombang $1310 \mathrm{~nm}$. Di sisi lain, panjang gelombang $1310 \mathrm{~nm}$ memiliki nilai bit rate dan BER yang lebih tinggi dibandingkan panjang gelombang $1550 \mathrm{~nm}$. Panjang gelombang $1550 \mathrm{~nm}$ lebih cocok untuk implementasi RoF dengan jarak jangkau yang lebih rendah dan kapasitas yang lebih tinggi dibandingkan $1310 \mathrm{~nm}$.

\section{DAFTAR PUSTAKA}

[1] A. S. Chahine, U. A. K. Okonkwo, and R. Ngah, "Study the Performance of OFDM Radio over Fiber for Wireless Communication Systems," in 2008 IEEE International RF and Microwave, 2008, pp. 335-338.

[2] A. M. Zin, M. S. Bongsu, S. M. Idrus, and N. Zulkifli, "An overview of radio-over-fiber network technology," 2010 Int. Conf. Photonics, ICP2010, pp. 0-2, 2010.

[3] Pooja, Saroj, and Manisha, "Advantages and Limitation of Radio over Fiber System," Int. J. Comput. Sci. Mob. Comput., vol. 45, no. 5, pp. 506-511, 2015.

[4] J. Guillory, "Radio over Fiber for the Furute Home Area Networks," University of ParisEst, 2012.

[5] A. Dixit, "Architectures and algorithms for radio-over-fiber networks," J. Opt. Commun. Netw., vol. 10, no. 5, pp. 535-544, 2018.

[6] Febrizal, "Evaluasi Kinerja Sistem OFDM Radio over Fiber (OFDM-RoF)," J. Sains dan Teknol., vol. 8, no. 1, pp. 13-17, 2009.

[7] S. Zhou et al., "Performance of optical OFDM transmission over RoF system with Mach-Zehnder modulator," in Proc. of SPIEOSA-IEEE Asia Communications and Photonics, 2011, vol. 8309, no. I, p. 83092D.

[8] J. D. Cepeda, S. I. Rodr, C. D. Mu, and M. Var, "Performance Evaluation of a real time OFDM Radio Over Fiber System at 2. $5 \mathrm{GHz}$ using Software Defined Radio SDR," in 2017 SBMO/IEEE MTT-S International Microwave and Optoelectronics Conference (IMOC), 2017.

[9] B. Ftaich-Frigui, C. Aupetit-Berthelemot, M. Mouhamadou, C. Kazmierski, C. Decroze, and D. Carsenat, "OFDM-WiMAX modulation of a reflective amplified modulator in radio-over-fiber context," IEEE Photonics Technol. Lett., vol. 23, no. 16, pp. 1109-1111, 2011.

[10] S. Mikroulis, M. P. Thakur, and J. E. Mitchell, "Comparison of OFDM standards for $60 \mathrm{GHz}$ SMF-MMF radio over fiber links," IEEE Int. Conf. Commun., vol. 2015Septe, pp. 1376-1379, 2015. 
[11] C. C. Wei, C. T. Lin, M. I. Chao, and W. J. Jiang, "Adaptively modulated OFDM RoF signals at $60 \mathrm{GHz}$ over long-reach $100-\mathrm{km}$ transmission systems employing phase noise suppression," IEEE Photonics Technol. Lett., vol. 24, no. 1, pp. 49-51, 2012.

[12] Y. M. Lin and P. L. Tien, "Next-generation OFDMA-based passive optical network architecture supporting radio-over-fiber," IEEE J. Sel. Areas Commun., vol. 28, no. 6, pp. 791-799, 2010.

[13] J. Zhang and N. Ansari, "On OFDMA resource allocation and wavelength assignment in OFDMA-Based WDM radioover-fiber picocellular networks," IEEE J. Sel. Areas Commun., vol. 29, no. 6, pp. 1273 1283, 2011.

[14] P. K. Gkonis, M. A. Seimeni, N. P. Asimakis, D. I. Kaklamani, and I. S. Venieris, "A new subcarrier allocation strategy for MIMOOFDMA multicellular networks based on cooperative interference mitigation," Sci. World J., vol. 2014, 2014.

[15] F. Wang et al., "Mobile WiMAX Systems : Performance and Evolution," IEEE Commun. Mag., no. October, pp. 41-49, 2008.

[16] X. Fernando, "Radio over fiber in multimedia access networks," in Proceedings of the 1st International Conference on Access Networks AccessNets '06, 2006, vol. 267.

[17] W. ForumTM, "Mobile WiMAX-Part 1: A Technical Overview and Performance Evaluation," White Pap. June, vol. 2.8, p. 15, 2006.

[18] A. E.-N. A. Mohamed, M. M. E. Elhalawany, A. N. Z. Rashed, and M. S. F. Tabbour, "High Transmission Performance of Radio over Fiber Systems over Traditional Optical Fiber Communication Systems using Different Coding Formats for Long Haul Applications," Int. J. Adv. Eng. Technol., vol. 1, no. 3, pp. 180-196, 2011. 